Res Mobilis Revista internacional de investigación en mobiliario y objetos decorativos Vol. 5, nº 6 (I), 2016

\title{
UM CRUCIFIXO DE ALTAR DO CEILÃO, EM MARFIM, DO SÉCULO XVII: CONSERVAÇÃO E RESTAURO, MATERIAIS, TÉCNICAS E DESAFIOS 17th CENTURY IVORY CRUCIFIX OF ALTAR FROM CEYLON: CONSERVATION AND RESTORATION, MATERIALS, TECHNIQUES AND CHALLENGES
}

Margarida Cavaco*

Laboratório José de Figueiredo. Direção Geral do Património Cultural

\section{Resumo}

Um Crucifixo de altar, em marfim do século XVII, tem sido objeto de interesse expositivo desde o século XIX. Ligado à arte da Expansão Portuguesa, esta peça conjuga uma vertente artística ecuménica, fruto das variadas ideologias religiosas que conviviam lado a lado no território indiano. Em 2012, integrou a exposição Arquitetura Imaginária, tendo o seu estado de conservação sido diagnosticado pelo Laboratório José de Figueiredo (LJF). O restauro iniciou-se no ano seguinte, nas instalações do LJF, culminado com a sua mostra no Museu Nacional de Arte Antiga (MNAA), sob a temática "Vita Christi. Marfins LusoOrientais", em 2013. A raridade do conjunto revela-se nas técnicas decorativas e construtivas utilizadas, bem como na riqueza dos materiais empregues, salientando-se as placas de marfim esculpidas, os cristais de rocha e os rubis cravejados na figura de Cristo. Cabe, aqui, apresentar a metodologia de intervenção desenvolvida pelo LJF bem como o tratamento, o estudo dos materiais e os desafios que surgiram no decurso deste projeto.

Palavras-chave: Marfim Luso-Oriental, século XVII, Conservação, Restauro, Cruz de Altar.

\section{Abstract}

An Altar Cross from the 17th century has been an object of interest for exhibition display since the 19th Century. Being linked to the Portuguese expansion history, it presents an ecumenical reading that is fruit of the different religious ideologies that cohabited, side by side, in the Indian Territory. In 2012 it was part of the exhibition "A Arquitetura Imaginária" being surveyed, in its sequence, by the National Conservation Institute Laboratório José de Figueiredo (LJF).Its conservation intervention and study took place during the following

\footnotetext{
*E-mail: mcavaco@dgpc.pt
} 
year at LJF premises culminating in its monstrance at the Museu Nacional de Arte Antiga (MNAA) exhibit entitled "Vita Christi. Marfins Luso-Orientais". The uniqueness of this object is seen in the decorative and construction techniques as well as in the richness of its materials, special focus to the low relief ivory plaques, the rock crystals, the inlayed ruby gems of the figure of Christ. The intervention methodologies, the material study and the challenges posed during this conservation project, will be presented herein.

Keywords: Luso-Oriental, Ivory, 17th Century, Conservation, Altar Cross

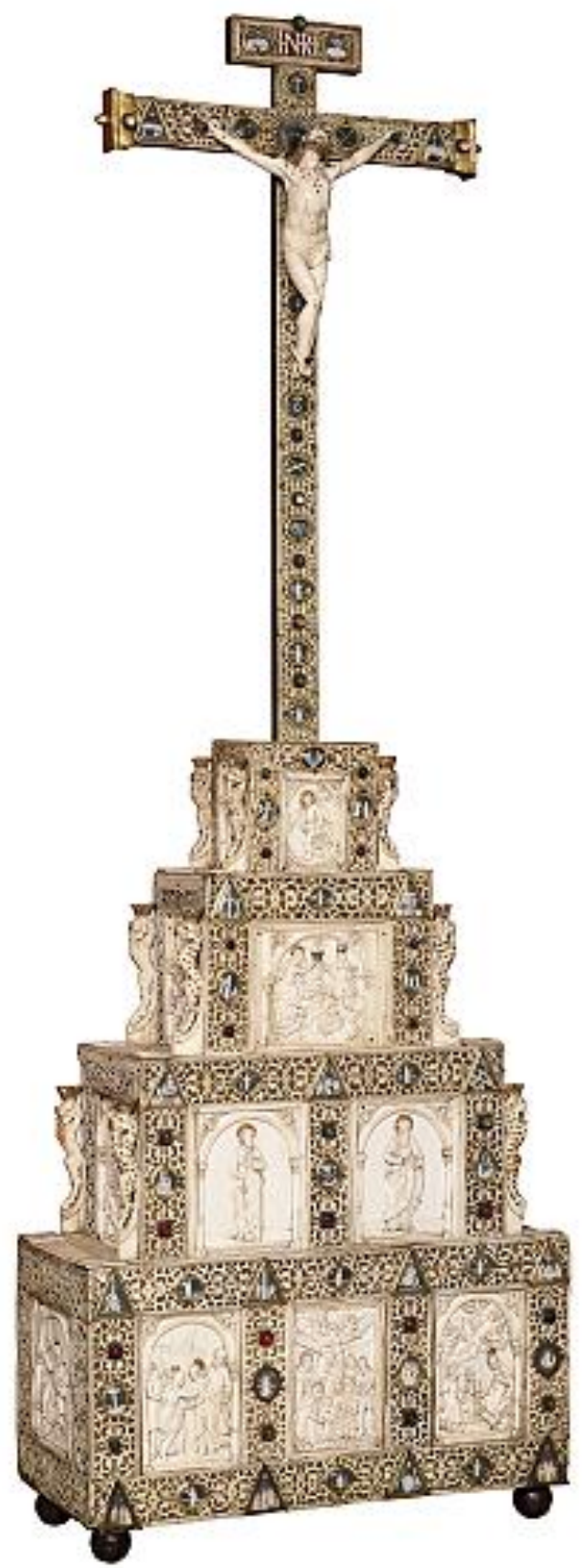

Fig.1. Crucifixo com Calvário em marfim. Século XVII. Dimensões em mm: 1520 x 520 x 210 (Altura x Largura $\mathrm{x}$ profundidade). 


\section{Introdução}

O artigo que aqui se apresenta incide sobre um projeto de estudo, conservação e restauro de um Crucifixo de Altar com base em forma de trono, em marfim, do século XVII. Demonstra o trabalho realizado no LJF, realçando as suas valências ao nível da conservação e do restauro bem como do estudo de materiais. É fruto de uma vasta equipa que se dedicou durante seis meses à recuperação meticulosa deste conjunto. A intervenção profunda desta obra teve como objetivo primordial devolver-lhe o seu aspeto original, restabelecer a sua estabilidade física e fazê-la perdurar na história. Neste projeto, expõem-se os desafios de atuação metodológica colocados pela presença de materiais compósitos e os resultados dos estudos levados a cabo durante a sua intervenção. (Fig.1)

Concluída a sua exibição na exposição Arquitetura Imaginária, em 2012, formou-se, então, uma equipa pluridisciplinar que pudesse levar a acabo uma intervenção de conservação e restauro que a peça necessitava de forma urgente ${ }^{1}$. Reuniram-se diversas vertentes do saber através dos historiadores do MNAA, dos investigadores do Vicarte da Universidade Nova de Lisboa, dos químicos e físicos do LJF e do Laboratório Hercules, bem como o "saber-fazer" e a experiência dos conservadores restauradores das áreas de escultura, papel, metais, pintura, mobiliário e têxteis, do LJF.

Se por um lado toda a investigação histórica foi coordenada pela Dra. Conceição Borges de Sousa ${ }^{2}$, a componente de estudo material, processos construtivos, técnicas decorativas e metodologias de conservação foram da responsabilidade do LJF.

A primeira questão que se colocou, desde o início, foi se este objeto é uma peça de mobiliário ou de ourivesaria, ou mesmo de escultura. Sabemos que se trata de forma inequívoca de um conjunto que pertence ao grupo das Artes Decorativas, de cariz religioso, e que estava exposta na capela particular do seu proprietário para o culto litúrgico diário. Da sua proveniência pouco se conhece. Os arquivos estão por explorar restando os escassos testemunhos orais dos proprietários. Não se sabe se foi uma encomenda, uma aquisição ou uma oferta. Apenas se confirma que em 1882 já pertencia à coleção dos Duques de Palmela, pois vem referenciada na Exposição Retrospectiva de Arte Ornamental Portugueza e Hespanhola, com a entrada de catálogo $n^{\circ} 310^{3}$.

Este conjunto, tal como outros objetos em marfim que integram coleções de museus nacionais, é produto da expansão portuguesa por diversas partes do mundo, mas de forma mais marcante em terras do Oriente. A sua produção é uma consequência dos diversos cruzamentos de culturas, comércio e religiões, relações que se traduzem nos materiais empregues e na temática decorativa. É uma peça elucidativa do poder catequético da missionação, comprovado nas placas de marfim em baixo-relevo, reunindo cenas da Vida da Virgem, os Doutores da Igreja, o Menino Jesus transportando os instrumentos da Paixão, os Evangelistas, São João Baptista, São Jerónimo, São Francisco e Santo António. Estas representações são emolduradas por finas placas de marfim "rendilhado", com simbologia característica de outras crenças. A utilização de motivos 
decorativos como o Kirtimuhka, os Hamas, os Sinha-yaris, lembra o revestimento exterior de cofres e de caixas de marfim, do século XVII, de produção cingalesa ${ }^{4}$.

Esta fusão de diversas ideologias e matérias-primas num só objeto é invulgar, bem como o seu tamanho desmesurado em que a base e o crucifixo medem 1,52 metros de altura convergindo, todavia, para um equilíbrio artístico harmonioso e bem programado do conjunto.

Sendo uma peça que se caracteriza por ser património artístico móvel é, também, de realçar o facto dos seus elementos constituintes terem chegado até aos nossos dias sem se terem separado, extraviado, ou subtraída uma das partes, pois são raros os exemplares de crucifixos que apresentam a cruz com a figura de Cristo. Mais surpreendente é o facto de a cruz ser de encaixar e não estar colada à base em escadório, união que facilmente permite, também, a separação destes elementos.

\section{Descrição e caracterização material}

De modo geral o conjunto é constituído por três elementos principais: a base, a cruz e a figura de Cristo crucificado. Apostos a estes elementos existe uma gramática decorativa em camadas, enaltecida por materiais sobrepostos como lâmina de cobre dourada, marfim recortado e vazado, cristais de rocha gravados e cabuchões coloridos com engastes em prata dourada.ase é executada em madeira exótica, formanda por blocos retangulares ocos que se sobrepõem, em forma de trono, elevando o nosso olhar para a cruz culminando na figura de Cristo, em marfim. $\mathrm{O}$ conjunto está assente em quatro pés esféricos, torneados em madeira de teca (Tectona grandis L.), que também se encontra na estrutura do crucifixo ${ }^{5}$. O escadório é formado por várias pranchas de madeira (com espessura de 25 mm.) de uma espécie tropical, de tom escuro, não se encontrando aparelhada. A construção dos degraus é tosca e não emprega assemblagens sofisticadas. As madeiras de cada patamar são unidas topo a topo, sem recorrer a qualquer tipo de união macho-fêmea. A fixação entre os diferentes degraus é feita com pregos de ferro forjados, de cabeça facetada por batimento. (Fig.2)

Nas superfícies lenhosas detetaram-se algumas marcas de ferramentas, nomeadamente instrumentos de marcação e de desbaste. $\mathrm{O}$ sulcado do graminho é bem visível no primeiro nível, marcando a dimensão das reservas a escavar, e os centros dos frisos de marfim vazados, a dispor pela superfície. Na espessura do rebaixo escavado (para embutir as placas em baixo-relevo) há marcas de supressão de matéria, coincidentes com a utilização do formão.

No fundo da base, emoldurada pelos quatro pés, encontra-se sulcada a data de 1650 (ou 1610?). Esta é apenas visível pela incidência de luz rasante, quando a base está deitada. 


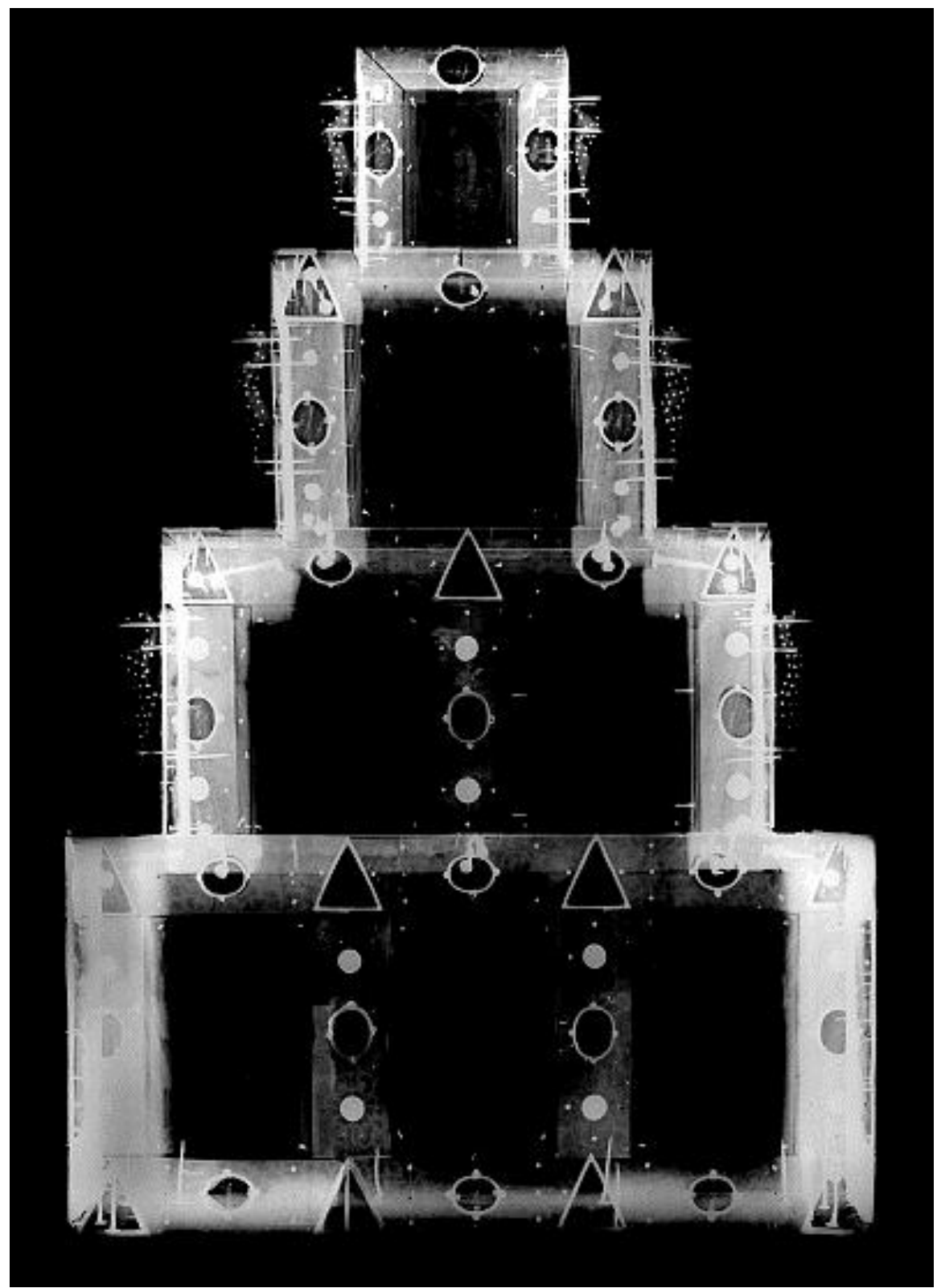

Fig. 2. Exame radiográfico permitindo visualização dos detalhes construtivos. Realizado pelo técnico Luís Piorro do LJF.

A parte da frente e das ilhargas da base, têm encastradas no suporte quinze placas de marfim, esculpidas em baixo-relevo, com temas religiosos que ocupam os quatro níveis da base. Têm como emolduramento o referido revestimento compósito que se estende, também, a toda a superfície frontal da cruz. É formado por lâminas de cobre, douradas pelo processo de amálgama de mercúrio, onde estão justapostas finas placas de marfim, profusamente recortadas com motivos vegetalistas e fixas com pregaria metálica dourada. A frente da peça é pontuada com vidros coloridos em cabuchão, intercalados com cristais de rocha gravados. Estes cristais são convexos e aparecem emoldurados com aros de cobre dourado, de formato oval e triangular, tendo como fundo um tecido. A gravação destes cristais é feita pelo reverso e preenchida com branco de 
chumbo, de modo a dar leitura à imagética religiosa representada ${ }^{6}$. Como fundo e a realçar o preenchimento branco existe um veludo de seda, com um tom predominantemente azul. Os fios de teia de fundo são amarelos e os fios de teia de pelo e de trama são azuis ${ }^{7}$.

Os frisos de marfim rendilhados preenchem a maioria das superfícies, variando a sua espessura entre $1,2 \mathrm{~mm}$ e $1,5 \mathrm{~mm}$. A sua fixação é feita com pregaria de cobre de cabeça dourada e nos topos dos degraus são utilizadas cavilhas de marfim para reforço das placas do mesmo material. Os frisos são aplicados em segmentos, sendo mais finos e estreitos na cruz, exibindo um trabalho de recorte mais minucioso. A sua união é quase impercetível, pois os motivos vegetalistas entrelaçam-se de forma contínua ocultando o espaço entre uniões (Fig.3).

A quantidade de marfim utilizada é tão vasta que para a execução dos frisos, das placas esculpidas em baixo relevo e para figura de Cristo o material foi retirado de grandes presas de elefante. Foi possível comprovar o seu comprimento quando se removeram todas as placas de baixos-relevos e se observou o canal pulpar pelo reverso de cada uma, dando a dimensão total da presa de onde foi extraído o marfim, atingindo cerca de um metro. Sabemos que a temática esculpida nas placas de marfim e nos cristais gravados é baseada em gravuras da época, que circulavam pela Europa e chegavam ao Oriente através da forte presença missionária ${ }^{8}$. Outras fontes de inspiração eram modelos transportáveis e de cópia fácil como placas esculpidas de pequenos trípticos, ou de missais.

A decorar o reverso da base existe uma policromia de desenho tosco, executada a ouro sobre fundo vermelho. Embora a sua leitura não seja integral, devido ao mau estado de conservação e inúmeros repintes, foi possível fazer o registo gráfico dos motivos que ainda subsistem. A decoração policroma que aqui se encontra é tecnicamente conseguida cobrindo a madeira de base com uma preparação à base de caulinite e a cor vermelha visível obtêm-se pela sobreposição de duas camadas de vermelhão e mínio aglutinados com goma laca. A decoração a folha de ouro é a última a aplicar, sendo por fim protegida por uma camada de goma laca (Fig.4.) ${ }^{9}$. 


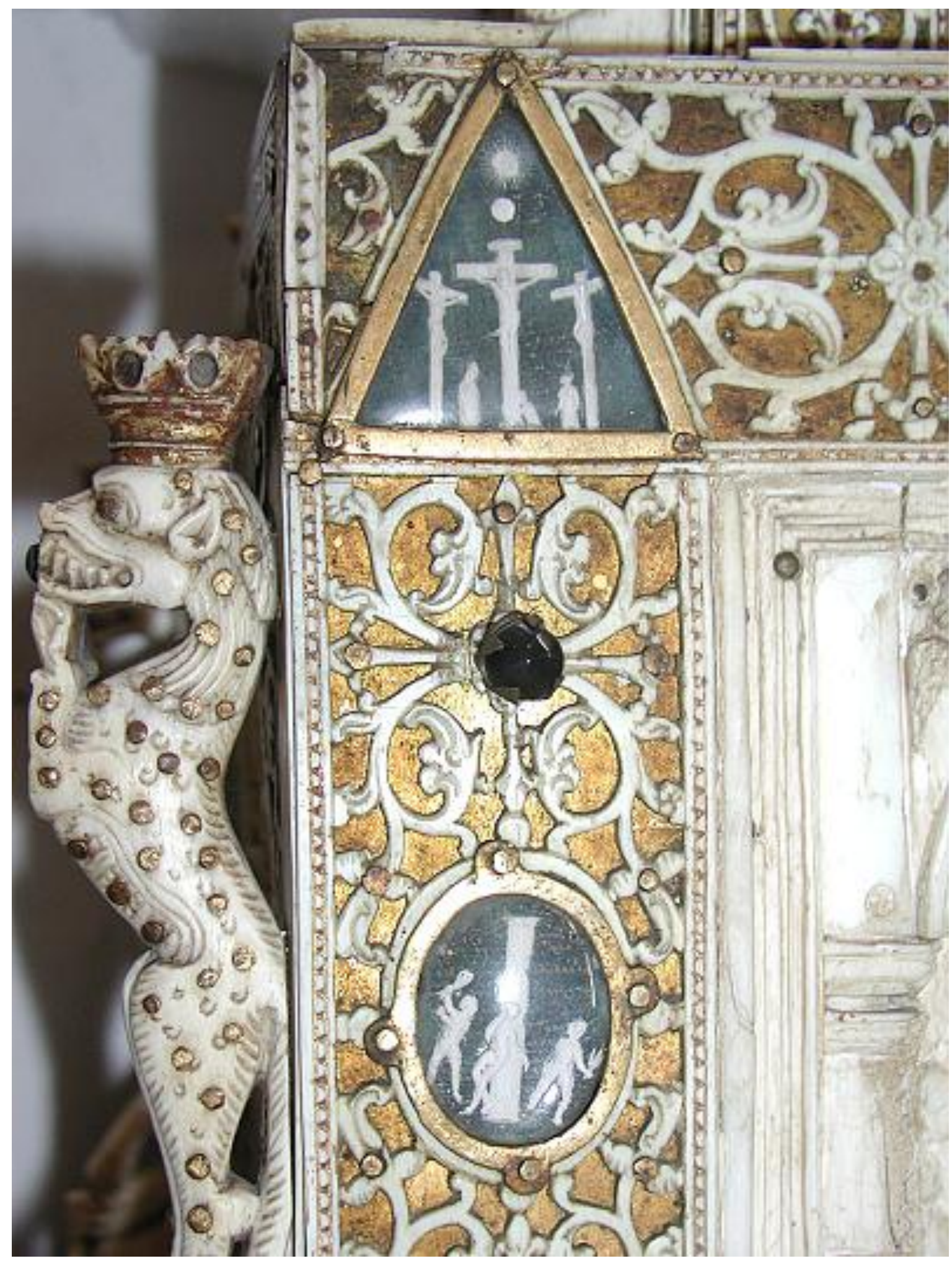

Fig.3. Pormenor da união dos frisos rendilhados. Último degrau do escadório. 



Fig.4. Documentação gráfica do reverso da base.

Pormenor decorativo do $2^{\circ}$ degrau e análise estratigráfica da policromia.

Existem vestígios de um traço dourado a delimitar cada degrau sendo cada um decorado individualmente, não apresentando o último vestígios de douramento, ainda que se suponha ter existido. A temática dominante é vegetalista, incluindo folhagens, ramos e flores de diversas espécies. Embora se reconheça uma relação visual entre os quatro degraus, a linguagem decorativa é, contudo, diferente: no primeiro, existem dois gamos afrontados entre folhas e flores; no segundo, a vegetação é mais elaborada e profusa, com elementos em forma de bolbos (que aparentam ser frutos), e flores, com dois ou três anéis de pétalas frisadas, envolvendo dois pássaros em pleno voo; no terceiro, as flores, tendo as pétalas riscadas com traço fino, lembram a representação de peónias, e as folhas são uma repetição das que aparecem nos degraus anteriores. Na distribuição dos motivos dourados subentende-se a preocupação da sua organização a partir de um eixo vertical, que tende a distribuir os elementos do lado esquerdo e do lado direito, de forma mais ou menos simétrica, para equilibrar a composição. A temática e a técnica apresentada aproximam-se da decoração interior das arcas de talha baixa executadas na Índia, durante o século XVI. Estas eram muitas vezes decoradas no seu compartimento interno, com um tom verde, vermelho ou preto, podendo ter decoração executada a ouro. Quando existe, esta é de matriz vegetalista e floral, envolvendo e dando ênfase aos animais representados como a fénix, a cegonha, a garça, o esquilo, o coelho e o 
gamo, sempre em poses de torção, numa representação pouco realista. Esta temática decorativa pode também encontrar referenciais no universo da produção nipónica cujos contadores recorrem aos mesmos artifícios decorativos nos seus painéis frontais e ilhargas. Relativamente à madeira de teca da cruz, (770 x $375 \mathrm{x}$ $15 \mathrm{~mm}$ ) esta foi escurecida com uma cera colorida, sendo o seu reverso, ao contrário do que sucede na base, sem qualquer tipo de decoração. Esta estrutura de madeira não é coeva da execução do restante objeto. O prumo da cruz original era de maiores dimensões encontrando-se, agora, preenchido com fragmentos de madeira para que esta pudesse ficar justa e se mantivesse na vertical. Ela é revestida pela mesma decoração compósita existente na base e encimada por uma placa retangular de marfim, vazada, com a inscrição "INRI", sobre um tom vermelho aplicado na lâmina metálica que lhe serve de suporte. Esta cor é conferida pela mistura de cochinilha e laca ${ }^{10}$.

Os frisos de marfim rendilhados são aplicados em segmentos, sendo mais finos e estreitos na cruz, e por debaixo da figura de Cristo existe a mesma distribuição de cristais de rocha gravados, alternados com vidros coloridos e doublets,em engastes de prata dourada.

A escultura de marfim de Cristo crucificado é parcialmente policromada, e esculpida em vulto perfeito, a partir de um só bloco de presa de elefante. Os braços são unidos ao corpo através de respiga interna reforçada com cavilha, encaixada pelas costas, não sendo o encaixe visível pela parte da frente do ombro da figura. Este pormenor técnico foi possível observar no exame radiográfico da escultura. A fixar as mãos e os pés do Cristo existem três cravos de prata em forma pirâmide quadrangular, que se prendem no reverso com porcas de rosca fina. A representação das escorrências de sangue nas costas da imagem é uma mistura dos corantes laca e cochinilha com proteína. A cor castanha dos cabelos foi obtida pelos pigmentos vermelhão e goetite com resina damar. Nas mãos, a coloração negra sobre o marfim é uma tonalização intencional, com uma têmpera de caseína e carvão; também na mão, a cochinilha foi usada no vermelho do sangue. As terminações das escorrências de sangue foram sulcadas no marfim para aí serem incrustados rubis, imitando gotículas, dos quais apenas subsistem quatro exemplares (Fig.5.)

Particularidade interessante, mas que é comum a quase todos os elementos executados em marfim, é a utilização da folha de ouro aplicada com bolus vermelho. Este foi identificado nos frisos rendilhados, nos baixos-relevos e nos leões adossados coroados que ladeiam os três últimos registos. Nos frisos rendilhados encontra-se na bordadura dourada em forma de linhas repetitivas de triângulos miudinhos. Nas placas iconográficas de marfim preenche as auréolas das figuras, as vestes (remate de mangas, bainhas e decotes) e os arcos e capitéis das colunas que emolduram as cenas. Nos leões apenas a coroa apresenta douramento e, através de análise estratigráfica, sabe-se que já foram redouradas, mas identificou-se que na sua composição original há uma mistura de mínio, goetite e caulinite, sendo a cor conferida pelos dois primeiros componentes. 




Fig.5. Pormenor dos pés de Cristo com rubis simulando gotículas de sangue. 


\section{Estado de conservação}

A peça apresentava vários problemas de conservação intimamente relacionados com a multiplicidade dos materiais constituintes e à sua complexa sobreposição em camadas, bem como a restauros antigos que foram danificando o objeto. De uma maneira genérica o que sobressai deste conjunto é o escurecimento de todo o marfim e das lâminas de cobre dourado, devido a acumulação de sujidade em zonas de difícil acesso.

O Cristo esculpido em marfim perdeu praticamente todas as incrustações de rubis, mas encontra-se em muito bom estado de conservação.

As placas de marfim em baixo-relevo foram sujeitas a agressivas ações de limpeza, fruto de manutenção constante, que resultaram no visível desgaste do douramento e depósitos de resíduos nos interstícios do entalhe. Algumas encontravam-se com fraturas e com perda de material, embora essas zonas estivessem colmatadas com massas e betumes, colocados em anteriores intervenções.

Os frisos de marfim recortado e vazado estavam fragilizados devido a lacunas provocadas pela presença de pregos de ferro, que já não eram os originais. A oxidação dos elementos ferrosos fez com que o marfim em seu redor se quebrasse e acabasse por se destacar. Muitos segmentos rendilhados apresentavam manchas de tom verde, devido aos produtos de corrosão das lâminas metálicas que foram contaminando o material ebúrneo.

As lâminas metálicas da cruz e da base encontravam-se num estado muito alterado, e praticamente inelegível, devido à sua degradação com produtos de corrosão de tom castanho e verde e com muita acumulação de sujidade aglomerada com resina damar.

A pregaria em cobre dourado, os engastes dos cabuchões e das molduras dos cristais gravados encontravam-se igualmente alterados. Algumas das molduras dos cristais gravados, assim como das lâminas de metal, já não eram originais. Os metais de remate do crucifixo, bem como os cravos e o resplendor de prata tinham perdido o brilho característico das superfícies metálicas.

O revestimento policromo do verso da base estava a destacar-se e com falta de aderência ao suporte, sendo visíveis zonas com empolamentos e lacunas, deixando a camada de preparação branca visível.

Os veludos que servem de fundo aos cristais de rocha estavam muito desvanecidos devido à ação da luz, alguns em desagregação total, com ácaros alojados no pêlo do têxtil e com poeiras acumuladas.

Detetaram-se, como já foi referido, diversos restauros efetuados ao longo do tempo, a grande maioria a colmatar faltas de marfim: execução de frisos rendilhados com mau recorte e indefinição de motivos, mas feitos com marfim; utilização de massas brancas a preencher faltas de elementos decorativos; preenchimento com papel e massas a ajustar as placas dos baixos-relevos nos seus nichos, para minimizar empenos e distorções; utilização de plástico, no topo do último degrau, imitando faixa de marfim. Para manter os frisos planos foram 
utilizadas colas que os fizessem aderir à lâmina metálica subjacente, tornando difícil a sua remoção sem quebra de material.

O conjunto das quinze placas de marfim em baixo-relevo, que reveste os degraus da base, evidenciavam empenamentos significativos tendo, em alguns casos, uma aparência curva. Esta alteração terá sido atenuada numa intervenção antiga, com enchimento dos espaços com ripas de madeira e papel.

\section{Metodologia de intervenção}

Como primeira reflexão sobre a metodologia de intervenção a implementar, surgiu a preocupação de definir a forma mais segura de executar as diferentes fases necessárias para a boa conservação do objeto: iniciar o tratamento com todos os materiais montados na sua estrutura ou se era possível fazer o seu desmonte, por camadas decorativas, e tratar cada material de forma isolada sem prejuízo de danificar os outros constituintes. As opiniões de toda a equipa de técnicos do LJF convergiram e, sem muitas dúvidas, optou-se por remover todos os materiais de revestimento decorativo até chegar à estrutura de madeira crua. Assim, em linhas gerais, era preciso proceder à remoção dos materiais, à sua limpeza, estabilização, consolidação, remoção de restauros antigos, reposição de elementos em falta e, por último, voltar a montar todos os elementos nos seus locais originais.

Para que a desmontagem fosse segura, e realizada de forma metódica, executaram-se suportes planos em espuma de poliestireno extrudido com as fotografias dos diversos degraus da base e da cruz impressas à escala natural. Estes suportes foram essenciais para depositar as placas dos baixos-relevos, as cavilhas de marfim, os frisos rendilhados, as chapas metálicas, a pregaria e os medalhões, à medida que se iam retirando do objeto e aguardavam tratamento. Para a fixação dos diversos elementos na espuma utilizaram-se alfinetes.

A desmontagem teve início removendo-se os três cravos da escultura de Cristo, que a fixavam na cruz, apeando-se a figura. De seguida, retiraram-se os pregos de fixação dos medalhões de cristal e os respetivos óvulos, vidros coloridos e o veludo. Só no fim se removeram, com espátulas finas e mini pé-de-cabra, os frisos rendilhados e as lâminas metálicas sob estes (Fig.6.) O mesmo método de remoção de camadas decorativas foi utilizado na base, deixando para o final a remoção das placas de baixo-relevo (Fig.7.)

Depois da separação de todos os componentes, os materiais foram tratados pelos Conservadores - Restauradores do LJF, nas respetivas secções especializadas em cada material. Todas as superfícies foram limpas, primeiramente por aspiração e, quando necessário, recorrendo a agentes químicos para complementar a limpeza e fazer a correta estabilização dos elementos a intervencionar ${ }^{11}$. 


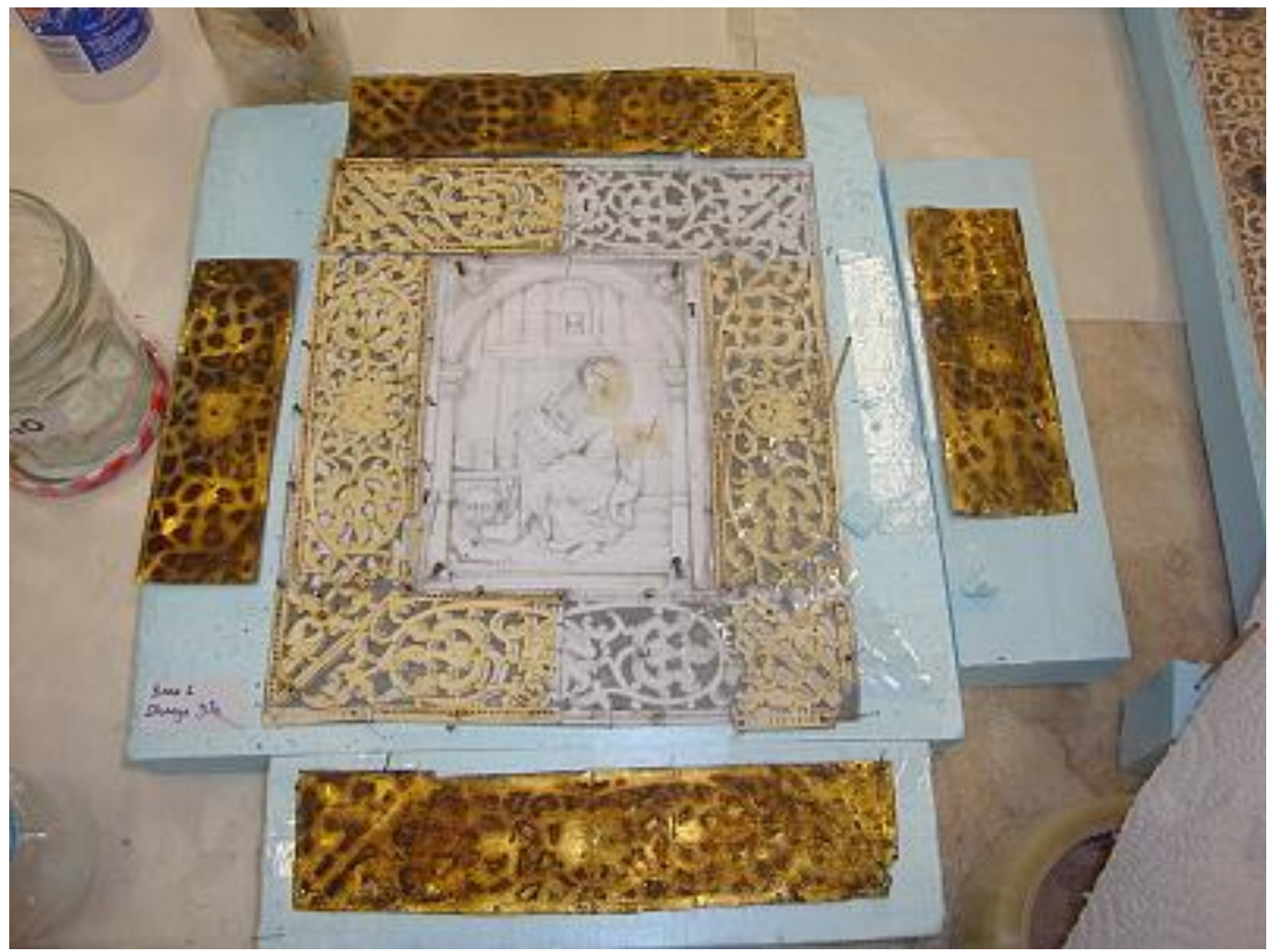

Fig.6. Execução de suportes em espuma de poliestireno extrudido com impressão em papel, da reprodução à escala natural de cada face da base. Fixação dos elementos removidos no suporte

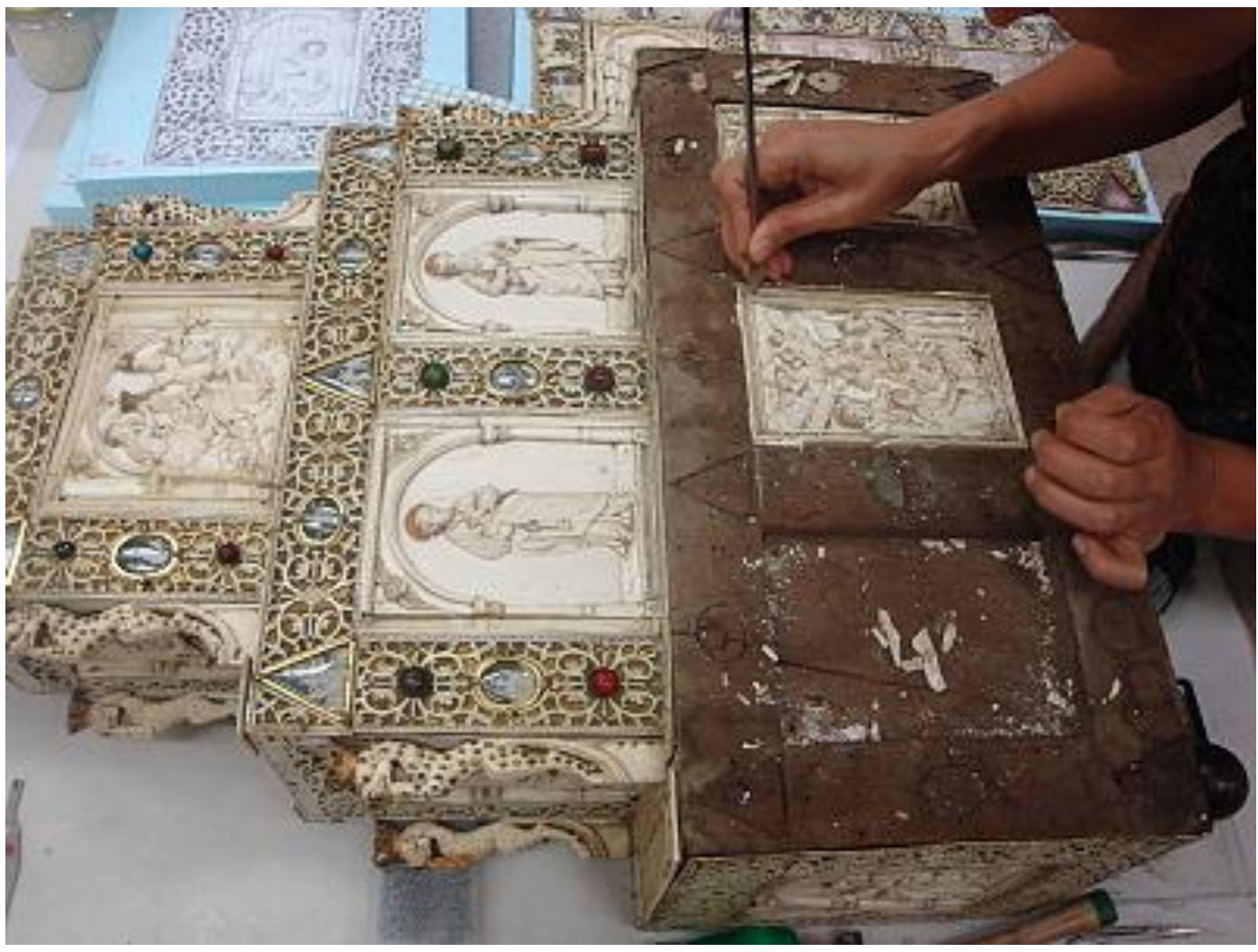

Fig.7. Desmontagem dos elementos decorativos da base. 
Tendo em conta os problemas colocados pelos elementos executados em marfim, estes foram os primeiros a ser sujeitos a tratamento. Os frisos rendilhados foram limpos com uma mistura de água, álcool e detergente neutro. Utilizaram-se pincéis de pelo curto para ajudar nesta operação. Para maior eficácia na limpeza nos interstícios e decorações reentrantes utilizou-se um sistema em "sandwich", que comprimia os frisos entre papel mata-borrão humidificado e fibra Gore-tex, que permitiu, simultaneamente, que a sujidade mais aglomerada pudesse ser humidificada localmente e removida, e que os frisos pudessem secar lentamente. Este processo possibilitou a planificação de algumas distorções existentes ${ }^{12}$.

O processo foi lento, mas permitiu controlar o tratamento e verificar o grau de limpeza através da utilização no papel mata-borrão. Até à recolocação dos elementos nos locais originais estes ficaram, mesmo depois de secos, sob pesos, para evitar deformações.

Para dar estabilidade física aos frisos de marfim e às finas placas que preenchem os topos da base foi necessário, pelo reverso, fazer reforços e colagens. Para tal, utilizou-se fita adesiva Filmoplast P90, fita de papel japonês, com $\mathrm{pH}$ neutro e isento de lenhina. Foram cortados pequenos fragmentos de modo a unir fissuras, fendas e aberturas. Para aumentar a sua adesão e dureza utilizou-se adesivo de Acetato de Polivinilo (PVA). Para evitar distorções as placas ficaram sob pesos, até a colagem estar bem seca. Nas placas dos topos, e visto a sua espessura ser muito fina, utilizou-se tripa natural desengordurada, colada com PVA.

Pela parte da frente dos frisos, em locais onde ocorrera perda de elementos decorativos refizeram-se esses elementos recorrendo a dois materiais distintos: papel (em pó e em folha) e marfim. Para as faltas de elementos de pequena dimensão utilizou-se o pó de papel tonalizado com aguarela "Windsor \& Newton" e o acabamento foi finalizado com bisturi e lixas de grão muito fino. Para grandes perdas de material fez-se o levantamento do desenho repetitivo e recortaram-se os motivos em falta em faixa de marfim (Fig.8.).

Um procedimento particular envolveu a execução dos elementos ovoides onde encaixam os medalhões. Fizeram-se "cordas" torcidas de papel japonês impregnado de PVA e foi-se dando a forma pretendida. Esta estrutura, depois de seca, foi coberta com a pasta feita de pó de papel e PVA. As "pontes" que se tiveram de estabelecer, entre elementos originais e preenchimentos seguiram este processo: encordoado de papel japonês e cola para dar uma estrutura primária e, de seguida, a sua cobertura com a pasta de pó de papel e adesivo. 

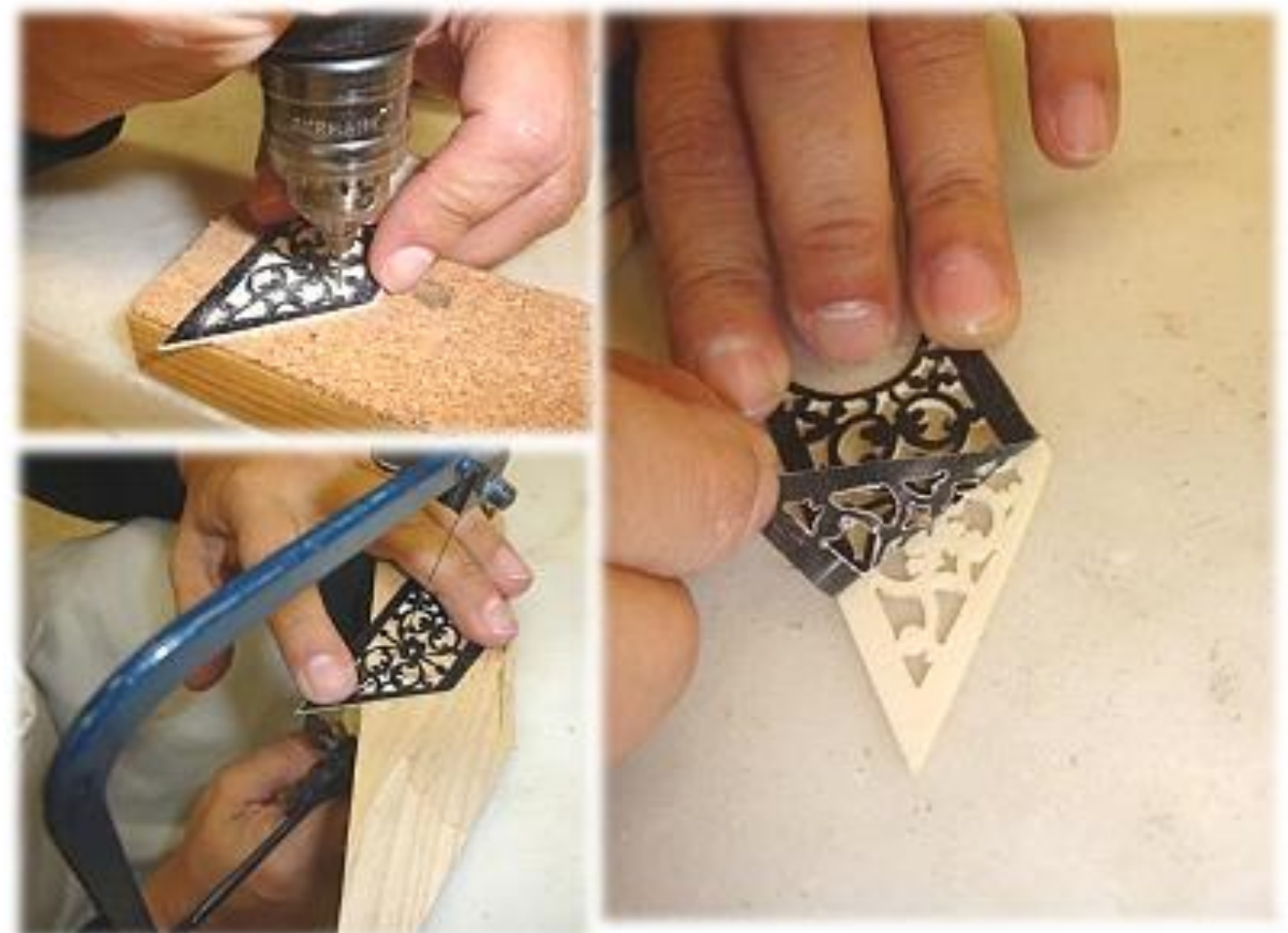

Fig.8. Execução de novos elementos em marfim. Corte e recorte manual dos motivos.

Quando à figura de Cristo e às placas esculpidas em baixo-relevo foram apenas limpos, mas aquando da remoção das placas do suporte estas revelaram algumas surpresas. Nos rebaixos onde encaixavam estavam dobrados papéis, organizados em conjuntos. No total, contabilizaram-se 59 fragmentos, entre estes dois eram manuscritos e estavam datados um de 1649 e o outro de 1650 . No fragmento datado de 1649, encontrou-se uma marca de água com três círculos, inserida num papel com duplo pontusal proveniente de papel Genovês, cujo fabrico se iniciou no século XVII e perdurou até meados do século XVIII. Foi encontrado, também, um papel que reúne duas marcas de água, do qual existem réplicas em registos de papéis manuscritos datados de 1762 e de 1772. Foi ainda encontrada uma marca de água, um barril, mas não foi possível balizar a sua utilização no tempo ${ }^{13}$.

Relativamente aos elementos metálicos como: as lâminas de cobre dourado, os engastes de cabuchões, o resplendor em prata dourada e as molduras dos cristais de rocha, foram todos submetidos a uma limpeza meticulosa para se remover o espesso filme de sujidade aglomerada e foram estabilizadas as camadas de corrosão ${ }^{14}$.

Os vidros coloridos e os cristais de rocha foram limpos com uma mistura de água desionizada e álcool. Por último procedeu-se à conservação dos óvulos e triângulos de veludo azul. Os que se encontravam em desagregação foram envoltos em tule, tingido da mesma cor do têxtil original, e todos foram limpos 
com um aspirador de sucção controlada. Restauros antigos diretamente relacionados com estes pequenos elementos foram removidos, substituindo os mais inestéticos como o plástico a imitar cristais de rocha e as molduras planas feitas em chapa de latão a simular aros de cobre dourado. Os plásticos foram trocados não por cristal de rocha, mas por vidros transparentes com a mesma curvatura e foram refeitas as molduras dos cristais com chapa de cobre dourada boleada nas arestas. A reprodução dos vidros ficou a cargo do Vicarte, da Universidade Nova de Lisboa ${ }^{15}$.

A madeira da estrutura, quer da cruz quer da base, foi limpa com pinceis de pelo curto e aspirada com a ajuda de trincha, fazendo movimentos circulares. Os pregos forjados utilizados na construção foram apenas intervencionados nas cabeças facetadas, uma vez que eram aquelas que se encontravam visíveis e oxidadas removendo-a mecanicamente com bisturi e mini-berbequim com escovas abrasivas. No final as áreas intervencionadas foram protegidas com cera.

A principal preocupação com as estruturas de madeira foi o preenchimentos dos orifícios deixados na superfície pela pregaria e elementos metálicos originais, que iriam ser utilizados para a remontagem das camadas decorativas. Para que todos os elementos a recolocar ficassem bem fixos ao suporte, os orifícios foram preenchidos com cavilhas de bambu sem utilização de adesivo, apenas inseridas por batimento e tonalizadas com vieux-chène muito diluído. Não se aplicou qualquer tipo de acabamento nas madeiras (Fig.9).

A policromia do reverso da base foi fixada com Klugel diluído em álcool a 6\%, fazendo várias aplicações desta mistura. Para a tonalização de zonas de preparação branca empregaram-se têmperas de cor adequada ao local a integrar.

Concluídos todos os tratamentos, levados a cabo individualmente em cada material, foi necessário proceder à etapa final: a montagem de todos os componentes nos seus locais originais. A tarefa iniciou-se de forma idêntica à do desmonte, partindo da cruz e só depois se revestindo a sua base. A precisão e rigor do trabalho exigiam que todos os elementos encaixassem exatamente suas furações originais. Para a montagem das lâminas metálicas, que se tinha de fazer em simultâneo com os frisos rendilhados de marfim, utilizaram-se alfinetes para apontamento inicial e só depois deste processo de fixação prévio se utilizaram os pregos de cobre dourados (Fig.10). Para esta tarefa, a equipa experiente tornou fácil o difícil, e tudo foi progredindo a bom ritmo, encaixando e fixando de forma meticulosa, todos os materiais (Fig.11). 


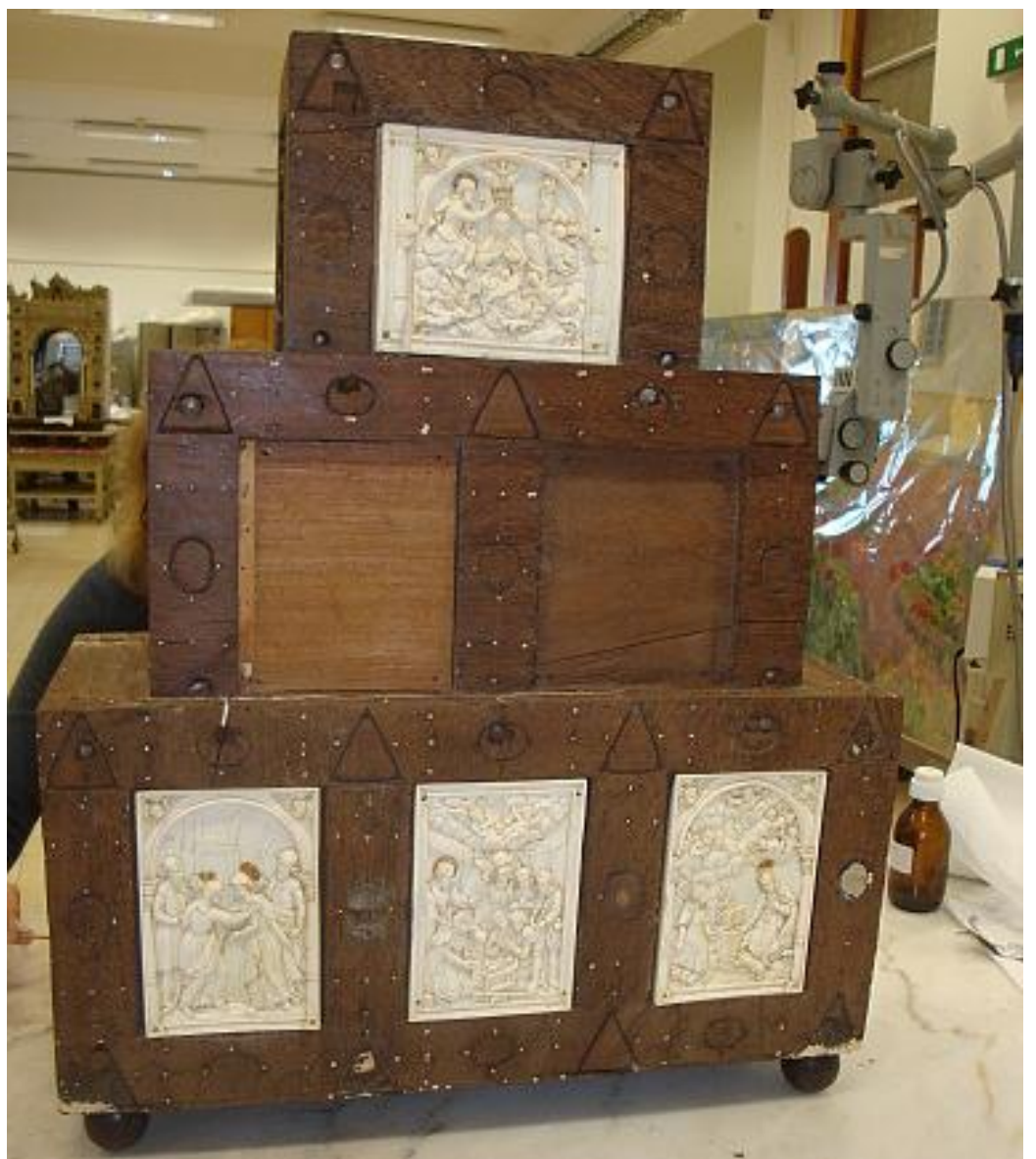

Fig .9. Montagem das placas esculpidas em baixo-relevo, depois do tratamento da madeira da base. São visíveis os preenchimentos dos orifícios da pregaria original com cavilhas de bambu.



Fig .10. Montagem dos elementos em conjunto, fazendo uma simulação com alfinetes antes da sua fixação definitiva. 


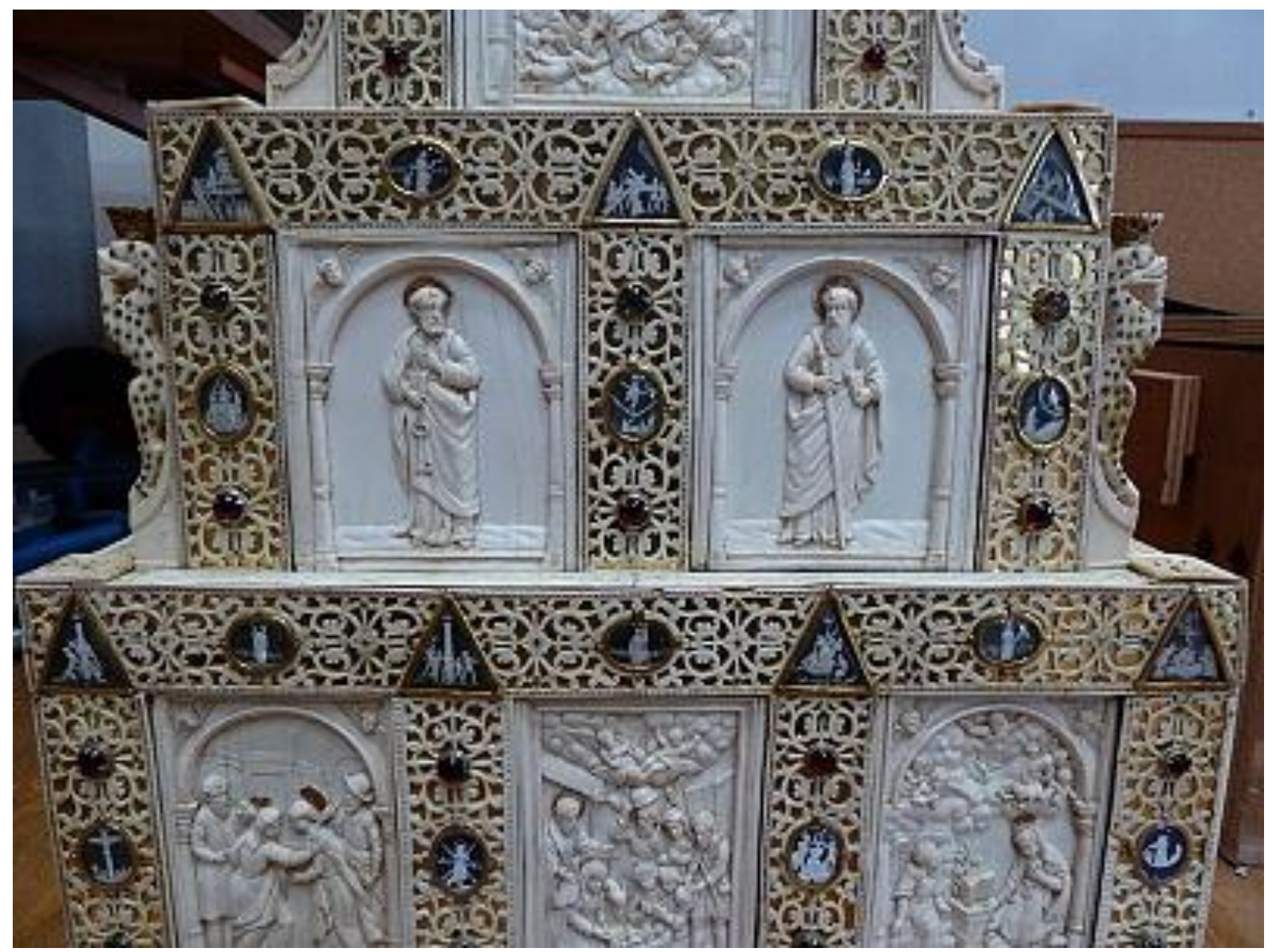

Fig.11. Pormenor frontal da base após conclusão do tratamento.

\section{Nota final}

Cada vez mais o trabalho desenvolvido na conservação e restauro, apoiado em métodos de exame e análise, tem-se revelado fundamental para uma melhor compreensão da memória artística material do passado. Os resultados que se vêem obtendo permitem compreender melhor as metodologias de trabalho, opções práticas de seleção de materiais, erros e arrependimentos, uma diversidade de elementos que nos permitem comunicar directamente com aqueles que executaram estes objectos. Se a História enquadra os acontecimentos e a História da Arte contextualiza as criações estéticas da Humanidade, à Conservação e Restauro cabe o diálogo quase directo com aqueles que trabalharam na construção das nossas memórias materiais.

Após a colocação dos restantes elementos, a peça ficou pronta e é hoje possível observá-la como, outrora, o fizeram pela primeira vez os seus donos. A paciente, meticulosa e morosa tarefa que constitui o trabalho de uma equipa de conservação e restauro de um objecto artístico é, finalmente, recompensada. A possibilidade de ver um objecto o mais próximo possível do que ele foi no momento da sua conclusão é o que há de mais semelhante ao viajar no tempo e constitui, talvez, o aspecto mais gratificante desta profissão ${ }^{16}$. 


\section{NOTES}

${ }^{1}$ Catálogo de Exposição; A Arquitetura Imaginária. Pintura, Escultura e Artes Decorativas, 2012. Lisboa, MNAA-INCM, $\mathrm{n}^{\circ}$ de entrada de catálogo 90, pp. 166-167.

${ }^{2}$ Conservadora de Mobiliário e Arte Oriental do MNAA. Investigadora e Comissária da Exposição Vita Christi. Marfim luso orientais. Sala do Tecto Pintado. MNAA, Dezembro 2013.

${ }^{3} \mathrm{Na}$ entrada de catálogo vem apenas descrita como Cruz de madeira e marfim feita de fragmentos de vários estylos. Altura 1m,52.Srs Duques de Palmella, Lisboa. Esta exposição, onde foram exibidos cerca de 4000 objetos, teve lugar no Palácio Alvor, no ano de 1882.

O conjunto, também, esteve exposto em 1983, no Mosteiro dos Jerónimos, onde decorreu a exposição XVII-Arte, Ciência e Cultura. Em 2001, sob a temática "Uma família de colecionadores-Poder e Cultura", dedicada exclusivamente à coleção dos Duques de Palmela, esteve exposta na Casa Museu Dr. Anastácio Gonçalves.

${ }^{4}$ Estes motivos decorativos encontram-sedisseminados pelos diversos patamares da base. Os Kirtimuhka (seres míticos parecidos com leões) aparecem nas placas de marfim rendilhadas como elemento central. Os Sinhayaris, que lembram representações de leões adossados, aparecem esculpidos em vulto perfeito, nas arestas de cada degrau. São representados coroados e com o corpo pontuado a pregaria dourada.O Hamas é uma ave que lembra uma mistura de pato e fénix e que na mitologia hindu é um ganso sagrado. A sua representação é feita aos pares e afrontados, em placas de marfim sulcado a baixa profundidade, nos topos dos degraus.

Sobre esta temática, consultar: SOUSA, Maria da Conceição; "Vita Christi Num Crucifixo com Calvário em Marfim" in VITA CHRIST - Marfins Luso-Orientais. Lisboa, MNAA, 2013, pp. 44-57.

${ }^{5}$ O estudo e identificação de todas as madeiras foram realizados pela Dra. Lília Esteves, Bióloga do LJF. A identificação da madeira que constitui a base ainda está em estudo.

${ }^{6}$ Este modo de trabalhar o cristal teve grande aperfeiçoamento em Itália, durante os séculos XVI e XVII. Nos elementos da base e da cruz o branco de chumbo é aglutinado com uma proteína animal. As cenas representadas aludem a momentos e símbolos da Paixão, à Ressurreição de Cristo e às figuras dos doze Apóstolos.

${ }^{7}$ A identificação e estudo técnico do têxtil foram realizados por Paula Monteiro da secção de Têxteis do LJF. Para mais detalhes sobre este assunto consultar: MONTEIRO, Paula et al; "Descobrindo a Cruz- apresentação e Análise de resultados do seu estudo e Conservação" in VITA CHRIST - Marfins Luso-Orientais. Lisboa, MNAA, 2013, pp. 70.

${ }^{8}$ A título de exemplo, um dos triângulos de cristal de rocha que tem gravada a cena da Flagelação, tem como referencial a gravura de Hieronymus Wierix (1553-1619), datada de 1593. Esta pode ser visionada na página online do British Museum, com o número de inventário 1868.0612.581.

${ }^{9}$ Análise laboratorial realizada por Maria José Oliveira do LJF.A análise das amostras foi efetuada num microdifractómetroBruker AXS com sistema de detecção em área (GADDS), modelo D8 Discover, equipado com âmpola de $\mathrm{Cu}-\mathrm{k} \alpha$, göbelmirror, detectorHiStar e colimador de $1 \mathrm{~mm}$ de diâmetro. A gama angular considerada situa-se entre os $9^{\circ}$ e os $100^{\circ}$ e o tempo de aquisição foi de $300 \mathrm{~s} \mathrm{com} \mathrm{um} \mathrm{passo} \mathrm{de} 0.02^{\circ}$. A tensão e a intensidade de corrente aplicadas ao tubo foram de $40 \mathrm{kV}$ e $40 \mathrm{~mA}$, respectivamente.

A identificação das fases presentes foi realizada através da base de dados internacional PDF-ICDD no software EVA da Bruker.

${ }^{10}$ A identificação destes compostos foi realizada por Ana Claro, no LJF. Todas as análises foram realizadas por cromatografia líquida de alta resolução com detetor de díodos acoplado (HPLC-PDA).

${ }^{11}$ Tal como o estudo e caracterização material,todo o processo de conservação e restauro foi, devido à complexidade de materiais e estruturas compósitas, à medida que os tratamentos iam avançando e as dúvidas iam surgindo, acompanhado de exames e análises laboratoriais complementares.

${ }^{12}$ Este procedimento e aconselhamento da utilização da fibra Gore-tex, foi acompanhado e orientado por Joana Campelo, Ana Magalhães e Filomena Vaz, da secção de Documentos Gráficos do LJF.

${ }^{13}$ Todo o tratamento e estudo destes exemplares em papel foram da inteira responsabilidade de Francisca Figueira, Conservadora-restauradora da secção de papel do LJF. Para mais detalhes sobre o estudo destes fragmentos consultar: FIGUEIRA, Francisca et al; Estudo de 59 fragmentos de papel encontrados na base de uma Cruz de Altar em marfim do século XVII. In Conservar Património, No19. ARP. Junho 2014, pp 21-34. 


\footnotetext{
${ }^{14}$ Todos os procedimentos efetuados nas superfícies metálicas e reprodução de emolduramentos de cristais de rocha, foram realizados na secção de Metais e Ourivesaria do LJF, pelas conservadoras-restauradoras Belmira Maduro e Mariana Cardoso.

${ }^{15} \mathrm{O}$ Vicarte é o centro de estudo de Vidro e Cerâmica para as Artes, da Faculdade de Ciências e Tecnologia da Universidade Nova de Lisboa e está sob a coordenação de Márcia Vilarigues e Robert Wiley

${ }^{16}$ Os créditos fotográficos das imagens apresentadas neste artigo são da DGPC-LJF.
} 